\title{
A rapid change in Earth's mantle geochemistry at 3.2 billion year ago points to an early start of plate tectonics
}

\author{
Hamed Gamal EL Dien ${ }^{1 *}$, Luc-Serge Doucet ${ }^{1}$, J. Brendan Murphy ${ }^{1,2}$, Zheng-Xiang Li ${ }^{1}$ \\ ${ }^{1}$ Earth Dynamics Research Group, The Institute for Geoscience Research (TIGeR), School of Earth \\ and Planetary Sciences, Curtin University, GPO Box U1987, Perth, WA 6845, Australia \\ ${ }^{2}$ Department of Earth Sciences, St. Francis Xavier University, Antigonish, Nova Scotia, Canada \\ * Corresponding author: \\ E-mail address: hamed.gamaleldien@postgrad.curtin.edu.au
}

Progressive mantle melting during the Earth's earliest evolution led to the formation of a depleted mantle and a continental crust enriched in highly incompatible elements. Reenrichment of Earth's mantle can occur when crustal materials begin to founder into the mantle by either subduction or, to a lesser degree, by delamination processes, profoundly affecting the mantle's trace element and volatile compositions. Deciphering when mantle re-enrichment/refertilization became a global-scale process would reveal the onset of efficient mass transfer of crust to the mantle and potentially when plate tectonic processes became operative. Here we document the onset of mantle reenrichment/refertilization by comparing the abundances of petrogenetically significant isotopic values and ratios of highly incompatible elements compared to lithophile elements in Archean to Early-Proterozoic mantle-derived melts (i.e., basalts and komatiites). Basalts and komatiites both record a step-change in mantle chemistry around 3.2 billion years ago (Ga) signifying a fundamental change in Earth geodynamics. This step-change is recorded in $\mathrm{Nd}$ isotopes and in key trace element ratios that reflect a fundamental shift in the balance between fluid-mobile and incompatible elements (i.e., $\mathrm{Ba} / \mathrm{La}, \mathrm{Ba} / \mathrm{Nb}, \mathrm{U} / \mathrm{Nb}, \mathrm{Pb} / \mathrm{Nd}$ and $\mathrm{Pb} / \mathrm{Ce}$ ) in basaltic and komatiitic rocks. These geochemical proxies display a significant increase in magnitude and variability after $\sim 3.2 \mathrm{Ga}$. We hypothesize that rapid increases in both mantle heterogeneity, as evidenced by Nd isotopes and fluid-mobile elements in the mantle, indicate the recycling of supracrustal materials back into Earth's mantle via subduction. Our new observations thus point to a $\sim 3.2$ Ga onset of global subduction processes via plate tectonics. 